\section{Doctor Humberto Del Pozo}

Recientemente falleció el Profesor Dr. Humberto Del Pozo Parada, uno de los pediatras más ilustres de la Medicina en nuestro país y padre de la Oncología Infantil Chilena.

Estudió medicina en la Universidad Católica de Chile y obtuvo su titulo de medico-cirujano en 1947. En los inicios de su carrera se desempeño como médico asistencial y docente en los Servicios y Cátedras de los Profesores Aníbal Ariztía y Adalberto Steeger. Entre 1959 y 1960 fue becado de pediatría en la Universidad de Paris y posteriormente de Oncología infantil en el Hospital Gustave Roussy de Paris.

En 1964 ingreso como pediatra al Hospital de Niños Dr. Luis Calvo Mackenna y en 1974 fue nombrado Profesor Asociado de la Universidad de Chile.

El Profesor Del Pozo tuvo una destacada actuación en la Pediatría chilena y fue maestro de muchas generaciones de médicos. Siempre destacó por sus especiales dotes como docente y clínico excepcional, enseñando la pediatría al lado de la cama del enfermo e inculcando el hábito de estudio y la importancia de la clínica para elaborar un diagnóstico diferencial $\mathrm{y}$ una hipótesis diagnóstica fundamentada y certera. Junto a eso predicó con el ejemplo su rigurosidad, honestidad, humildad, respeto por los pacientes y su familia y la relación médico paciente como valor fundamental.

En 1968 organizó el Servicio de Oncología del Hospital Calvo Mackenna que fue pionero en nuestro medio y del cual fue jefe hasta 1993. Durante ese periodo vivió intensamente el desarrollo de la disciplina y le dio realce a la asistencia, docencia e investigación. Formó a numerosos hémato-oncólogos y su personalidad influyó decisivamente en la mantención de una incesante actividad de los grupos hématooncológicos de nuestro país y Latinoamérica.

Participó activamente con grupos comunitarios de ayuda a los niños con cáncer y configuró equipos interdisciplinarios que son el sostén fundamental del manejo de una patología con trascendentes proyecciones, sociales y humanas.

En 1987, junto a la Dra. Eugenia Emparanza Jefa de Oncología del Hospital Roberto Del Río y en el marco de la Comisión Nacional del Cáncer, fundó el Programa Infantil Nacional de Drogas Antineoplásicas (PINDA), del Ministerio de Salud. Este programa, único en Latinoamérica, atiende al $80 \%$ de la población infantil con cáncer de nuestro país, con índices de curación similar a los de EE.UU. y Europa.

En 1993 se acogió a retiro del sistema público de salud, aunque continuó ligado al Hospital aportando su valiosa experiencia y conocimientos siempre actualizados.

Hoy, quienes tuvimos el privilegio de ser sus discípulos y en nombre de los millares de niños chilenos curados de cáncer, le rendimos con admiración y respeto un postrer homenaje animados por el ejemplo de su larga y fructífera carrera profesional en que privilegió siempre al niño enfermo, ofreciéndole la mejor calidad de atención y demostrando su alto nivel de excelencia no solo científica sino que también humana.

Su legado permanecerá para siempre en las futuras generaciones de médicos y en la historia de la Pediatría de nuestro país

Dra. Victoria Beresi Reyes 